\title{
TRAINING IN PHYSIOTHERAPY FOR LEPROSY WORKERS
}

\author{
by R. S. BUKER, M.D., D.P.H.
}

Course conducted at the McKean Leprosy Colony, Chiengmai, Thailand, 8th January - 12th February, 1963

One of the weakest links in the total therapeutic programme for leprosy patients has been physiotherapy. This applies in most places of the world except those few areas which have realized its value and have put in full time units to meet the needs. Even these full time units often need to be rejuvenated as it is easy to get 'routine' in a task which has to be done daily for years. Another weak point of our physiotherapy programme is that we fail to get the activity down to the root of the problem. The early case of deformity usually gets no instructions as to what he should do to prevent further deformity and the majority of cases have no instructions as to the value of prevention and how it can be accomplished.

\section{Preparation for the Physiotherapy Course in Thailand}

In all Thailand there are two trained physiotherapists. One is a young lady recently trained at Vellore. She is working in the Government Leprosy Programme. The other is a missionary of the Overseas Missionary Fellowship working in the Christian Hospital at Manorom where there is a splendid Leprosy Wing as a part of the general hospital. Physiotherapy of the hands and feet is being used at the McKean Leprosy Colony and in over 50 clinics being conducted by the various Missions in Thailand. No carefully planned courses for physiotherapy training, however, have been available for the many leprosy workers needing it.

Dr. Hasselblad, President of the American Leprosy Missions, feeling that here was a place that leadership was needed, arranged with Mrs. Ruth Thomas Thein (formerly in charge of the physiotherapy training at Vellore) to conduct such courses; one in Thailand, one in Vietnam, and one in Hongkong. Normally the length of a course of physiotherapy is twelve to eighteen months. As it is impossible to give this length of time by most of our workers, it was decided to attempt a course of 6 weeks' duration, emphasizing the basic needs.

\section{The Course}

Fourteen participants actually took the course. There were a few visitors for a day or more. The class was divided into groups, about equal in size, one group who knew English and one group which required interpretation into Thai. The lectures were translated into Thai by Acharn Prachim R.N. assistant supervisor of nurses at the 
McCormic Hospital. She had studied in America and handled the medical terminology with great ease. The entire course was, therefore repeated during the six weeks. Mrs. Thein lectured on the basic anatomy to one group in the morning and repeated it in the afternoon to the second group. Mr. Thein, a Vellore trained physiotherapist, took the other group, giving a short lecture on methods, using the remainder of the half day having the class do actual physiotherapy on the patients. This practical work added $100 \%$ to value of the course. The course was conducted at Chiengmai, at the McK.ean Leprosy Colony. Here there are 500 patients with ample number of all kinds needing physiotherapy. Full facilities of wax baths and electricity were available. Pre- and post-operative physiotherapy was not emphasized due to the shortness of the course. Several post-operative cases, however, were dealt with showing marked improvement following the physiotherapy.

All who participated in the course observed crooked fingers become straight as they put on daily finger casts; dropped feet became markedly improved from special exercises in three weeks time; post-operative cases of feet and hands which had not been properly exercised changed from failure to success under this therapy. It was realized afresh that surgery of the hands and feet is useless without pre- and post-operative physiotherapy. People with facial paralysis actually took on new life and hope, though nothing was done for them except physiotherapy. One case, a young man of 22 years, who had suffered many things at the hands of many socalled doctors, was made new again. His dropped foot and early crippling were almost completely cured. All this happened during the course. None of those who took the course will ever belittle physiotherapy as a real tool in the therapeutics of leprosy cripples.

There was no attempt to use Faradic and Galvanic currents to locate muscle damage. Vibrators and Infra-red lights were utilized but are not essential to those having no electricity.

\section{Summary}

Six missionaries and eight paramedical workers (nationals of Thailand) took the course. One doctor, six nurses, one physiotherapist, and six paramedical workers made up the group. Four different missions, The Christian and Missionary Alliance Mission, The Southern Baptist Mission, The Overseas Missionary Fellowship of the China Inland $\mathbf{M}$ ission and the Presbyterian Mission were represented.

Out of this course it is expected several other teaching facilities will develop. The Overseas Missionary Fellowship will teach nurses and nurses aids, active work on pre- and post-operative physiotherapy will continue at the Manorom Christian Hospital. 
The Christian and Missionary Alliance Mission will introduce a part time four year course in physiotherapy in its Maranatha Bible School for leprosy patients.

The Southern Baptist Mission will promote the use of physiotherapy in its outside clinics reaching the early cases as far as possible together with active physiotherapy teaching in its new hospital yet to be finished.

The Presbyterians will continue to give instruction to paramedical workers in physiotherapy at the Chiengmai McKean Leprosarium.

A continued effort is needed in all places doing clinic work to disseminate preventive and corrective physiotherapy methods for those suffering from leprosy. This course is making it increasingly possible to do this. 